\title{
Use of intraocular lenses in children with traumatic cataract in south India
}

\author{
Michael Eckstein, P Vijayalakshmi, Milind Killedar, Clare Gilbert, Allen Foster
}

\begin{abstract}
Aims-To assess the long term results of intraocular lens (IOL) implantation for traumatic cataract in young children in a developing country.

Methods-Prospective hospital based study of 52 children (age 2-10 years) undergoing unilateral cataract extraction and IOL insertion for traumatic cataract performed by a single surgeon in south India. Children were reviewed regularly and followed up initially for 3 years.

Results-There were no serious operative complications. Clinically significant posterior capsule opacification was almost universal (92\%) and YAG capsulotomy or membranectomy was performed on 48 eyes. Some degree of pupil capture affected $35 \%$ of eyes and was complete in $6 \%$. Visual acuity was $6 / 12$ or better in $67 \%$ of eyes at the last follow up examination. Conclusion-The visual acuity results 3 years after implantation of posterior chamber IOLs in older children with traumatic cataracts in south India were encouraging. In developing countries where follow up is unreliable it is essential to plan to clear the axial part of the posterior capsule either at the time of surgery or soon afterwards.
\end{abstract}

(Br F Ophthalmol 1998;82:911-915)

The use of intraocular lenses (IOLs) in infants and young children remains a controversial subject but there have now been many reports from the developed world which show good visual results following posterior chamber lens implantation in children older than 1 year.

In developing countries contact lenses are not an option for correction of aphakia following unilateral cataract extraction and IOLs offer the only realistic solution to early and good visual rehabilitation. In many developing countries affordable high quality IOLs are now readily available. ${ }^{1}$

Because children from poor rural communities tend not to return for clinic follow up and secondary procedures, retrospective reviews may underestimate complications following surgery, particularly posterior capsule opacification which may take many months to occur. We therefore undertook a prospective study of children with traumatic cataract between the age of 2 and 10 years who were eligible to have an extracapsular cataract extraction (aspiration) and IOL insertion. The aim was to assess whether use of IOLs might be safe and appropriate for this distinct population of children.
Materials and methods

Eighty four children with a unilateral traumatic cataract who were 10 years old or less presented to the paediatric eye clinic at the Aravind Eye Hospital over a 9 month period in 1993-4. All the children had a full ocular examination performed by one ophthalmologist. Whenever possible children were examined on the slit lamp microscope and by direct and indirect ophthalmoscopy after pupil dilatation. Cataracts were documented by photography using the slit lamp or operating theatre microscope.

All children between the age of 2 and 10 years who had not had any previous eye surgery and who required cataract surgery were eligible to be enrolled. Children with central corneal lacerations or other obvious extensive ocular trauma that was likely to affect visual outcome were excluded from the study. Parental informed consent was obtained in all cases.

To improve compliance with follow up a series of incentives was used which included free treatment, travel expenses for all visits, free spectacles and medication, as well as reimbursement for lost parental earnings. Parents were contacted by post 2 weeks before each visit became due. If they failed to turn up a second letter was sent. Children who failed to turn up after the second letter were traced with a home visit and asked to return.

A total of 52 children fulfilled the eligibility criteria and were enrolled. Of the 32 children who were not included, five were less than 2 years old, 16 lived too far away for regular follow up, and the remainder had undergone previous primary repairs or had extensive corneal trauma. All 52 eyes had an extracapsular cataract extraction with a posterior chamber IOL implant. The surgery was performed by a single experienced paediatric ophthalmologist and children were followed up according to a defined protocol.

The children were assessed daily after surgery by a single observer and were normally kept in hospital for 3 days following surgery. Children were reviewed after 4 weeks, 3 months, 6 months, 1 year, and then annually. Examination included slit lamp biomicroscopy, indirect ophthalmoscopy, measurement of intraocular pressure with Goldman tonometer or Keeler Pulsair 2000, refraction, and assessment of visual acuity.

SURGICAL PROCEDURE

All procedures were performed under general anaesthesia without muscle relaxants. Preoperatively, pupils were dilated with phenylephrine $2.5 \%$ and cyclopentolate $1 \%$. 


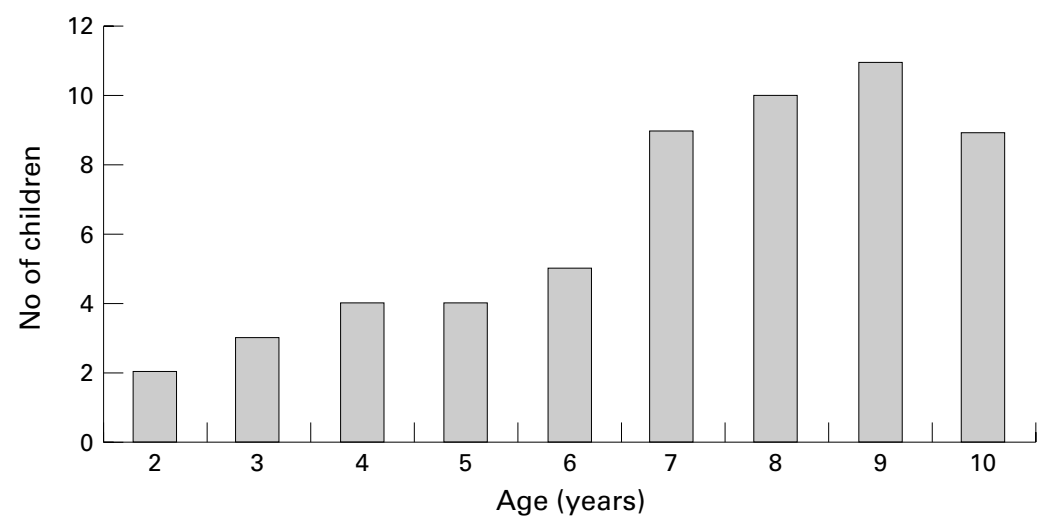

Figure 1 Age at presentation of 52 children with traumatic cataract.

The ocular adnexa and skin surrounding the eye were cleaned with $5 \%$ povidone-iodine, the surgical field draped with sterile towels and the eye irrigated with sterile saline solution. A lid speculum was inserted and a superior rectus suture attached. A superior conjunctival peritomy was created followed by a partial thickness limbal incision. A full thickness incision was made centrally and an irrigating cystitome inserted into the anterior chamber to produce a circular "can opener" type capsulotomy. Ringer lactate solution was used as the intraocular irrigating solution. A Simcoe irrigation aspiration cannula was used to remove the lens material. The limbal section was enlarged and a locally manufactured 6.0 $\mathrm{mm}$, three piece all PMMA biconvex IOL (Aurolab) with $\mathrm{C}$ loops and a $13.5 \mathrm{~mm}$ total diameter was manipulated into the capsular bag whenever possible. Air or a Viscoelastic was used to maintain the depth of the anterior chamber. A peripheral iridectomy was performed and the section was closed with four 10-0 nylon sutures. Residual Viscoelastic was removed with the irrigation aspiration cannula. After the superior rectus suture was removed, gentamicin $5 \mathrm{mg}$ and dexamethasone $2 \mathrm{mg}$ were injected subconjunctively into the lower fornix. The eye remained padded until the first postoperative examination.

A combination of gentamicin $0.3 \%$ and Betnesol $1.5 \%$ (betamethasone) were normally given six times a day to the operated eye after the first examination on day 1 . If the clinical situation warranted more frequent drop application or different drops, this was recorded on the appropriate form. Drops were reduced slowly over the following 6 weeks.

Intraocular lens power calculations were made using the SRK II formula on the basis of axial length (A-scan) and keratometric readings. Whenever corneal trauma precluded accurate keratometry the measurements from the fellow eye were used.

All visual acuity testing was performed by a single trained examiner in the same brightly lit room. Visual acuity was measured using Keeler acuity cards, Cardiff cards, and Snellen charts with letters in the Tamil language. All visual acuity results were converted into log MAR units for analysis. The best corrected visual acuity was recorded following refraction. Spectacles were prescribed at the first postoperative visit if required.
Complications at follow up visits were recorded on the appropriate proforma. Anterior chamber inflammation was graded between 0-3 (absent $/$ mild $=0$, greater than 50 cells visible in a $2 \times 1 \mathrm{~mm}$ slit beam at 45 degrees of oblique illumination $=1$, fibrin $=2$, pupillary membrane $=3$ ). Posterior capsule opacification (PCO) was classified into three types: type 1, PCO not seen in the central visual axis, seen only when the pupil is dilated and direct ophthalmoscopy gives a clear view of the fundus; type 2, PCO seen in the central visual axis in an undilated pupil. The fundus details are only minimally obscured; type 3, $\mathrm{PCO}$ is seen in the central visual axis in an undilated pupil. The fundus details cannot be clearly made out.

A diagnosis of glaucoma was made if the IOP was $>21 \mathrm{~mm} \mathrm{Hg}$ and the optic disc showed signs of increased cupping or if the IOP was consistently higher than $26 \mathrm{~mm} \mathrm{Hg}$. Pupil capture was recorded if all or part of the optic of the posterior chamber IOL was "captured" anterior to the iris. Lens tilt was recorded if severe enough to affect visual acuity.

Data were entered onto dBase IV and analysed with EPI-INFO 6 . The Student's $t$ test and Mantel-Haenszel $\chi^{2}$ test were used to determine associations.

\section{Results}

There were 41 boys and 11 girls. The mean age at time of surgery was 7.2 years (range 2-10 years, SD 2.26 years) (Fig 1). Three quarters of children came from rural areas and cataract from penetrating injury was four times as common as blunt injury.

The mean time between injury and surgery was 10.4 weeks (range 1-60 weeks): $56 \%$ of children had surgery within 1 month, $81 \%$ within 3 months, and $87 \%$ within 6 months of the injury. The mean follow up time after surgery was 2.9 years. All children attended review at 3 months, $48(92 \%)$ at 1 year, and 47 $(90 \%)$ at the 3 year follow up examination. None of the five children who were lost to follow up over the first 3 years after surgery could be traced even after home visits.

\section{COMPLICATIONS}

\section{Peroperative and early postoperative}

There were no cases of inadvertent posterior capsule rupture but three eyes had posterior capsule tears related to the original injury. Intraocular lenses were sulcus fixated in these eyes after the vitreous had been cleared from the anterior chamber with a vitrectomy cutter. There were no cases of iris prolapse, choroidal haemorrhage, or endophthalmitis. In 14 cases $(27 \%)$ viscoelastics were required during IOL insertion when air would not maintain the anterior chamber against the positive pressure from the vitreous. There were 10 children $(19 \%)$ who developed severe anterior uveitis (grade 1-3) and required intensive topical steroids in the early postoperative period. The severity of the uveitis was not significantly associated with time between the original injury and surgery. 


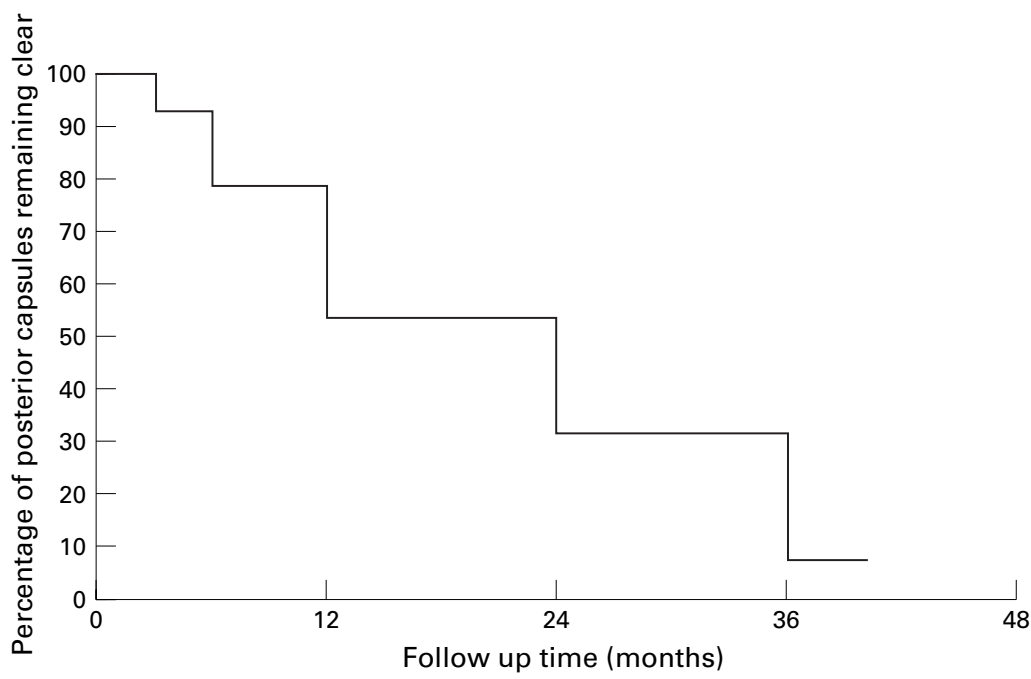

Figure 2 Kaplan-Meier curve illustrating the time between surgery and secondary procedure to remove the posterior capsule in 49 eyes with intact posterior capsule at time of surgery.

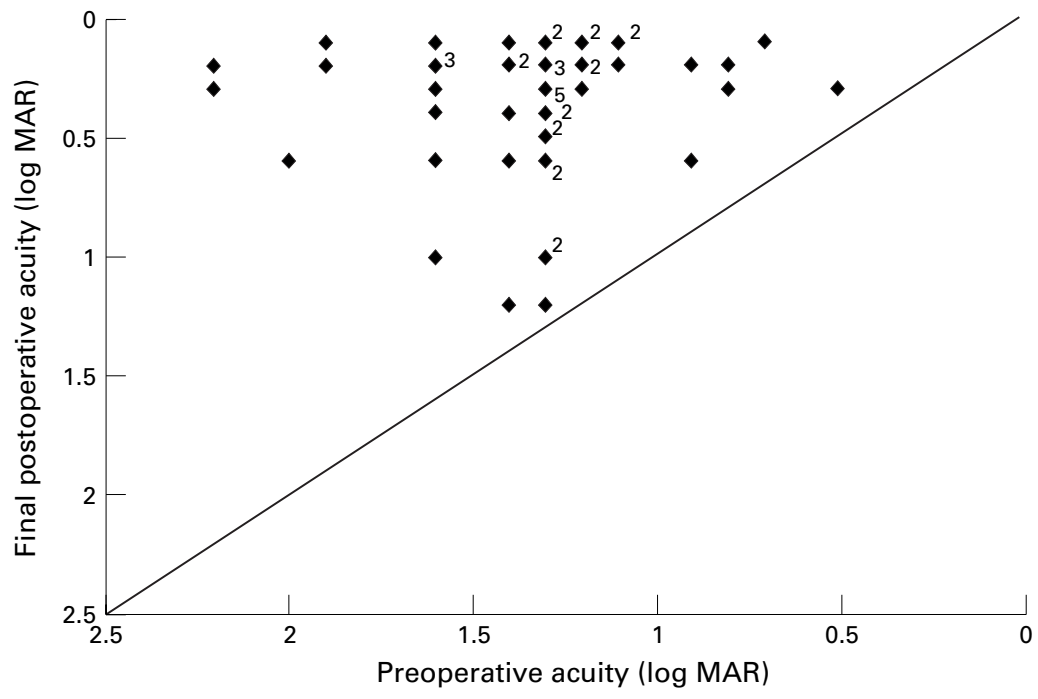

Figure 3 Graph comparing best corrected preoperative and final postoperative visual acuity in 52 eyes with intraocular lenses. Points above the line of equality represent improved visual acuity. (Numbers refer to identical points.)

\section{Late postoperative}

Almost all eyes (92\%) with an intact capsule developed clinically significant posterior capsule opacification (type 3) and required further intervention. More than one third of eyes $(35 \%)$ had some degree of pupil capture and in three $(6 \%)$ cases this was complete with the entire lens optic anterior to the pupil. Because the pupil capture did not affect the visual acuity or threaten the corneal endothelium it was managed conservatively in all cases. Pupil capture was not associated with severity of preoperative, immediate postoperative, or delayed inflammation (grade $\geqslant 1$ ). No eyes developed pupil block glaucoma and all the peripheral iridectomies appeared to be functional. There were no cases of open or closed angle glaucoma diagnosed up to and including the last follow up visit.

\section{Secondary procedures}

In 33 eyes a single YAG capsulotomy was sufficient to treat the posterior capsule opacification, but in six cases either a further
Table 1 Best corrected visual acuity in Snellen equivalents before and after surgery

\begin{tabular}{lccccc}
\hline & \multicolumn{2}{c}{ Preop } & & \multicolumn{2}{c}{ Last follow up visit } \\
\cline { 2 - 3 } Snellen acuity & No & $\%$ & & No & $\%$ \\
\hline $6 / 6-6 / 18$ & 0 & 0 & & 39 & 75 \\
$<6 / 18-6 / 60$ & 6 & 12 & & 11 & 21 \\
$<6 / 60-3 / 60$ & 27 & 52 & & 2 & 4 \\
$<3 / 60$ & 19 & 36 & & 0 & 0 \\
Total & 52 & 100 & & 52 & 100
\end{tabular}

YAG laser session or surgical membranectomy was required to clear the visual axis. In nine cases the capsule opacification was too advanced or the child too uncooperative for a laser capsulotomy and a surgical membranectomy was performed. The Kaplan-Meier graph (Fig 2) illustrates the time between surgery and secondary intervention in the 49 children who had an intact posterior capsule at the time of surgery and shows that nearly $50 \%$ of eyes had required a further procedure within the first 12 months of the initial surgery.

\section{VISUAL OUTCOME}

Visual acuity improved in all eyes following surgery and the comparison between preoperative acuity and final acuity is represented graphically in Figure 3. Points above the line of equality represent visual improvement following surgery. At the final follow up 35 eyes $(67 \%)$ of 52 patients had a best corrected visual acuity of $6 / 12(\log$ MAR 0.3$)$ or more and $47(90 \%)$ eyes had an acuity of $6 / 24(\log$ MAR 0.6) or more (Table 1). Visual failure $(\log$ MAR $>0.5$, Snellen equivalent <6/19) at the last review was due to amblyopia in six eyes, corneal scarring in four eyes, and one macular hole. Good visual outcome $(>6 / 12)$ was not associated with age, time between injury, and surgery or postoperative inflammation.

Thirty two eyes of 42 children (76\%) who had near vision tested could see better than N6 with appropriate spectacle correction. All children had binocularity assessed at each follow up examination with the TNO chart and Worth 4 dot test. Thirty seven children $(71 \%)$ had evidence of binocular function at their last follow up visit.

\section{Postoperative refraction}

The mean axial length measured before surgery was $22.5 \mathrm{~mm}$ (range $21-24.5 \mathrm{~mm}$ (SD $0.8 \mathrm{~mm})$ ). The scatter of axial length against age is plotted in Figure 4 and shows little increase above 2 years of age. Because all children in this study were more than 2 years old, the lens power was calculated for emmetropia rather than assuming myopia may develop later. Mean spherical equivalent postoperative refraction at the last visit was $+0.5 \mathrm{D}$ (range $-1 \mathrm{D}$ to $+2 \mathrm{D}$. (SD $0.64 \mathrm{D})$ ). There were no cases of clinically significant anisometropia and no eyes had a postoperative refraction more than $2 \mathrm{D}$ different from the expected refraction. 


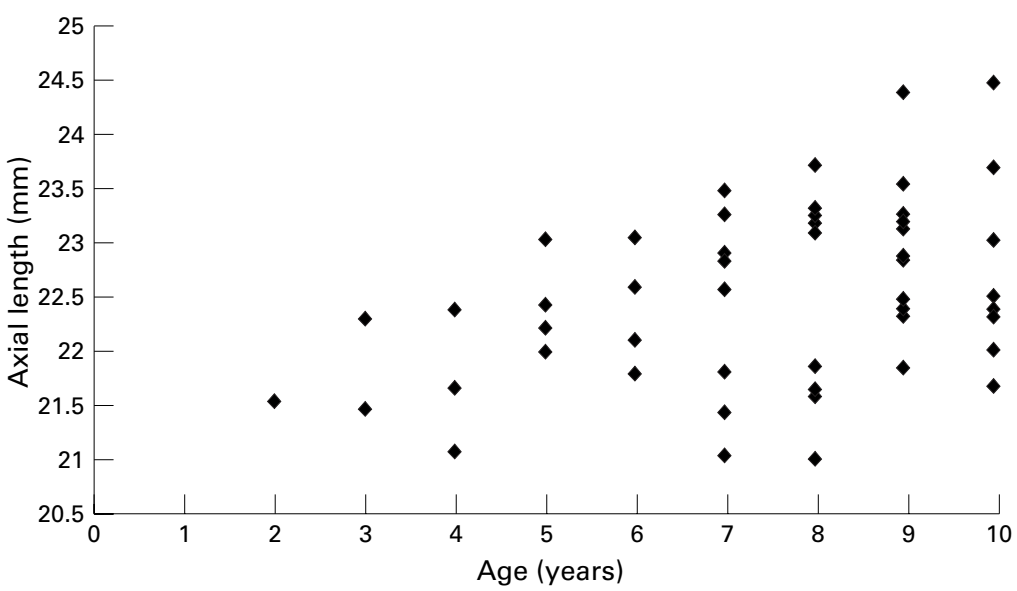

Figure 4 Axial lengths of eyes with traumatic cataract before surgery.

Table 2 Complications following IOL implantation for both traumatic and non-traumatic childhood cataract

\begin{tabular}{lccccc}
\hline First author, year, ref & $\begin{array}{l}\text { No of eyes } \\
\text { in series }\end{array}$ & $\begin{array}{l}\text { Severe } \\
\text { uveitis } \\
(\%)\end{array}$ & $\begin{array}{l}\text { Pupil } \\
\text { capture } \\
(\%)\end{array}$ & $\begin{array}{l}\text { Post-capsule } \\
\text { opacification } \\
(\%)\end{array}$ & $\begin{array}{l}\text { Age at } \\
\text { surgery } \\
\text { (years) }\end{array}$ \\
\hline Bienfait $1990^{16}$ & 23 & 0 & 9 & 83 & $0.4-11$ \\
Markham $1992^{17}$ & 16 & 12 & - & 56 & $0.4-8$ \\
Kora $1992^{18}$ & 25 & - & 12 & 44 & $5-15$ \\
Gupta $1992^{9}$ & 22 & 22 & 9 & 27 & $3-11$ \\
Vats $1993^{10}$ & 40 & 25 & 37 & - & $0.5-12$ \\
Koenig $1993^{19}$ & 8 & - & - & 37 & $4-17$ \\
Menezo $1994^{20}$ & 178 & 9 & 8 & 49 & $0.3-18$ \\
Brady $1995^{21}$ & 45 & - & 7 & 60 & $1-18$ \\
Kanawati $1995^{12}$ & 67 & 13 & - & 28 & $0.1-15$ \\
Crouch $1995^{22}$ & 34 & - & - & 53 & $2-16$ \\
Knight-Nanan $1996^{23}$ & 24 & 12 & 8 & 96 & $0.1-12$ \\
Plager $1997^{24}$ & 79 & - & 1 & 100 & $0.8-17$ \\
Ainsworth $1997^{25}$ & 55 & 5 & 5 & - & $2-16$ \\
\hline
\end{tabular}

\section{Discussion}

In India eye care and cataract surgery is provided free or at a nominal charge in the government and non-profit hospitals. Although the eye care services are free, the patient incurs substantial expenses in order to access them. The sum total of these costs including travel, loss of earnings, food, medications, and spectacles inhibits the number of parents who are willing to bring their children for surgery or follow up.

This prospective study was undertaken to evaluate the complications and visual outcome of IOL implantation in children with unilateral traumatic cataract in a developing country where follow up, treatment of amblyopia, contact lens correction, and access to health care are limited. In rural south India, contact lenses are not commonly used. The expense of replacing lenses together with the risks of infection, poor compliance, and limited follow up restrict their use to children from well motivated and "wealthy" families in large cities.

IOL implantation in children has been viewed with considerable caution in the past $^{2-4}$; Infants have a higher proportion of postoperative complications as a result of the inflammatory and fibrotic responses. The long term effects of PMMA in children's eyes is not established. Hypermetropia decreases markedly over the first 2 years of life in most children and therefore the required full correction for aphakia at 3 months of age is likely to become markedly overcorrected 2 years later.
Despite this, IOL implantation in children has become more popular in recent years in the developed world and is rapidly becoming the preferred means of optical correction in older children. ${ }^{5}$ The benefit of IOLs may ironically be greatest in areas of the world where other forms of visual correction such as contact lenses are not appropriate or available and anisometropia precludes spectacle use. Inexpensive, yet high quality, IOLs are now widely available in India and many ophthalmic units are able to perform microsurgical techniques.

In general the rate of serious complications following cataract surgery and IOLs is low but almost all of the studies are retrospective and the age of children and type of cataract are very variable both within and between series (Table 2). The result of IOL insertion in a child under 1 year with bilateral congenital cataracts is very different from a 10 year old with a traumatic cataract. The rapid growth phase of the eye has been completed by age 2 years ${ }^{6}$ and adult type lenses are appropriate. In children younger than this, implant size and power are difficult to determine.

In our series pupil capture was common, but interestingly was not associated with postoperative inflammation. Pupil capture may have occurred as a resukt of the heavily pigmented irises, the propensity to form posterior synechiae, and the use of a flexible three piece IOL which despite every effort, was often difficult to place successfully in the capsular bag. Newer techniques such as capsulorhexis will improve lens centration and this, as well as surface modified lenses, forward angulation of the lens haptics, and larger optics are likely to reduce the incidence of pupil capture in the future. ${ }^{7}$

Other studies from India have shown a high rate of secondary surgical intervention particularly among children less than 2 years old. ${ }^{8}$ Among older children results have been more encouraging ${ }^{9} 10$ but inflammatory pupil block glaucoma following posterior chamber IOL implantation was common in a series where no peripheral iridectomy had been performed. ${ }^{11}$ In a study of 67 eyes from children with IOLs following surgery for non-traumatic childhood cataract from the West Bank and Gaza with a follow up of 12-38 months no serious lens induced complications were reported. ${ }^{12}$

Posterior capsule opacification in young children after an extracapsular cataract extraction is rapid and almost universal. In our series $92 \%$ of children had required further intervention within 3 years of follow up. In our population, where secondary intervention is problematic, removal of the central posterior capsule at the time of surgery or immediately afterwards is likely to be beneficial. Buckley et $a l^{13}$ successfully avoided any secondary intervention for posterior capsule opacification by performing a standard endocapsular technique followed by a pars plana anterior vitrectomy and posterior capsulotomy in 20 children and Gimbel and DeBrott ${ }^{14}$ has advocated a posterior capsulorhexis at the time of surgery. This procedure is technically difficult in infant eyes and where ketamine anaesthesia or general anaesthesia without muscle relaxant is used the 
Table 3 Visual acuity of eyes with posterior chamber IOLs following surgery for traumatic cataracts

\begin{tabular}{lclll}
\hline First author, year, ref & $\begin{array}{l}\text { No of eyes } \\
\text { in series }\end{array}$ & $\begin{array}{l}\text { \% Eyes with } \\
\text { acuity 6/12 }\end{array}$ & $\begin{array}{l}\text { Age at surgery } \\
\text { (years) }\end{array}$ & $\begin{array}{l}\text { Mean follow up } \\
\text { (years) }\end{array}$ \\
\hline Bienfait $1990^{16}$ & 23 & 70 & $0.4-11$ & 6.5 \\
Gupta $1992^{9}$ & 22 & 45 & $3-11$ & 0.9 \\
Vats $1993^{10}$ & 23 & 57 & $4-12$ & - \\
Koenig $1993^{19}$ & 8 & 87 & $4-17$ & 0.8 \\
Menezo $1994^{20}$ & 103 & 77 & $3-18$ & - \\
Crouch $1995^{22}$ & 10 & 80 & $3-12$ & 2.2 \\
Churchill $1995^{26}$ & 15 & 62 & $2-15$ & 4.2 \\
Brady $1995^{21}$ & 20 & 70 & $2-14$ & 1.5 \\
Knight-Nanan $1996^{23}$ & 3 & 66 & $3-5$ & 2.3 \\
Plager $1997^{24}$ & 9 & 89 & - & 2 \\
\hline
\end{tabular}

positive vitreous pressure makes it hazardous. Early YAG laser capsulotomy following surgery has been successful ${ }^{15}$ and we now perform a YAG laser capsulotomy on compliant children within 2 days of surgery before discharge.

Visual acuity results from recent series following posterior chamber IOLs for traumatic cataract are shown in Table 3 . These are encouraging and results from our series compare favourably with those from the developed world. Amblyopia was the most frequent cause of avoidable visual loss in our series and the recognition and treatment of amblyopia in young children should be a priority. Education of parents, explanation of simple patching techniques, and close follow up of younger children at risk of amblyopia are very important.

\section{Conclusion}

In this selected group of older children with unilateral traumatic cataract who have IOLs, the visual outcome and low rates of serious complication are encouraging. Our clinical practice has been altered because of the high rates of pupil capture, postoperative inflammation, and posterior capsule opacification such that we now attempt capsulorhexis rather than a canopener anterior capsulotomy, use a 6.5 mm single piece all PMMA IOL, use orbital floor steroids (methylprednisolone acetate 40 $\mathrm{mg}$ ) at the end of the surgery, and try to perform early YAG laser capsulotomies before hospital discharge.

This study was supported by Sightsavers International and British Council for Prevention of Blindness.

1 Natchiar G, Robin AL, Thulasiraj RD. Attacking the back$\log$ of India's curable blind. The Aravind eye hospita model. Arch Ophthalmol 1994;112:987-93.
2 Hing S, Speedwell L, Taylor D. Lens surgery in infancy and childhood. BrF Ophthalmol 1990;74:73-7.

3 Wilson-Holt N, Hing S, Taylor D. Bilateral blinding uveitis in a child after secondary intraocular lens implantation for unilateral congenital cataract. F Pediatr Ophthalmol Strabismus 1991;28:116-18.

4 Masket S. Lens implantation consultation section. $f$ Cataract Refract Surg 1991;17:512-18.

5 Wilson ME, Bluestein EC, Wang XH. Current trends in the use of intraocular lenses in children. $\mathcal{F}$ Cataract Refract Surg 1994;20:579-83.

6 Wilson ME, Apple DJ, Bluestein EC, et al. Intraocular lenses for pediatric implantation: biomaterials, designs, and sizing. F Cataract Refract Surg 1994;20:584-91.

7 Basti S, Ravishankar U, Gupta S. Results of a prospective evaluation of three methods of management of paediatric cataracts. Ophthalmology 1996;103:713-20.

8 Vasavada A, Chauhan $\mathrm{H}$. Intraocular lens implantation in infants with congenital cataracts. F Cataract Refract Surg $1994 ; 20 \cdot 592-8$.

9 Gupta AK, Grover AK, Gurha N. Traumatic cataract surgery with intraocular lens implantation in children. $f$ Pediatr Ophthalmol Strabismus 1992;29:73-8.

10 Vats DP, Banerji A. IOL implantation in paediatric age group. Afro-Asian f Ophthalmol 1993;12:338-41.

11 Vajpayee RB, Angra SK, Titiyal JS. Pseudophakic pupillary block glaucoma in children. Am f Ophthalmol 1991;111: 715-18.

12 Kanawati CA. Intraocular lens implantation in children in the West Bank and Gaza. Eye 1995;9:783-93.

13 Buckley EG, Klombers LA, Seaber JH, et al. Management of the posterior capsule during pediatric intraocular lens implantation. Am f Ophthalmol 1993;115:722-8.

14 Gimbel HV, DeBroff BM. Posterior capsulorhexis with optic capture: maintaining a clear visual axis after pediatric cataract surgery. 7 Cataract Refract Surg 1994;20:658-64.

15 Atkinson CS, Hiles DA. Treatment of secondary posterior capsular membranes with the Nd:YAG laser in a pediatric population. Am f Ophthalmol 1994;118:496-501.

16 Bienfait MF, Pameijer JH, Wildervanck de Blecourt-Devilee $M$. Intraocular lens implantation in children with unilateral traumatic cataract. Int Ophthalmol 1990;14:271-6.

17 Markham RH, Bloom PA, Chandna A, et al. Results of intraocular lens implantation in paediatric aphakia. Eye 1992;6:493-8.

18 Kora Y, Inatomi M, Fukado Y, et al. Long-term study of children with implanted intraocular lenses. $f$ Cataract Refract Surg 1992:18:485-8.

19 Koenig SB, Ruttum MS, Lewandowski MF, et al. Pseudophakia for traumatic cataracts in children. Ophthalmology 1993;100:1218-24.

20 Menezo JL, Esteve JT, Perez-Torregrosa VT. IOL implantation in children-17 years' experience. Eur 7 Implant Refract Surg 1994;6:252-6.

21 Brady KM, Scott Atkinson C, Kilty LA, et al. Cataract surgery and intraocular lens implantation in children. $A m \mathcal{F}$ Ophthalmol 1995;120:1-9.

22 Crouch ER Jr, Pressman SH, Crouch ER. Posterior chamber intraocular lenses: long-term results in pediatric cataract patients. F Pediatr Ophthalmol Strabismus 1995;32 210-18.

23 Knight-Nanan D, O'Keefe M, Bowell R. Outcome and complications of intraocular lenses in children with cataract. I Cataract Refract Surg 1996;22:730-6.

24 Plager DA, Lipsky SN, Snyder SK, et al. Capsular management and refractive error in pediatric intraocular lenses. Ophthalmology 1997;104:600-7.

25 Ainsworth JR, Cohen S, Levin AV, et al. Pediatric cataract management with variations in surgical technique and aphakic optical correction. Ophthalmology 1997;104:1096101.

26 Churchill AJ, Noble BA, Etchells DE, et al. Factors affecting visual outcome in children following uniocular traumatic cataract. Eye 1995;9:285-91. 